\title{
CONF- $950412--57$
}

UCRL-JC-118958

PREPRINT

\section{An In Situ High Voltage Electron Microscopy Technique for the Study of Deformation and Fracture: In Multilayered Materials}

M. A. Wall

T. W. Barbee, Jr.

T. P. Weihs

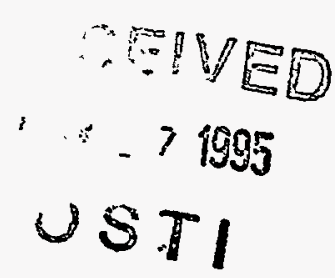

This paper was prepared for submittal to MRS 1995 Spring Meeting, San.Francisco, CA

April 17-21, 1995

April 14, 1995

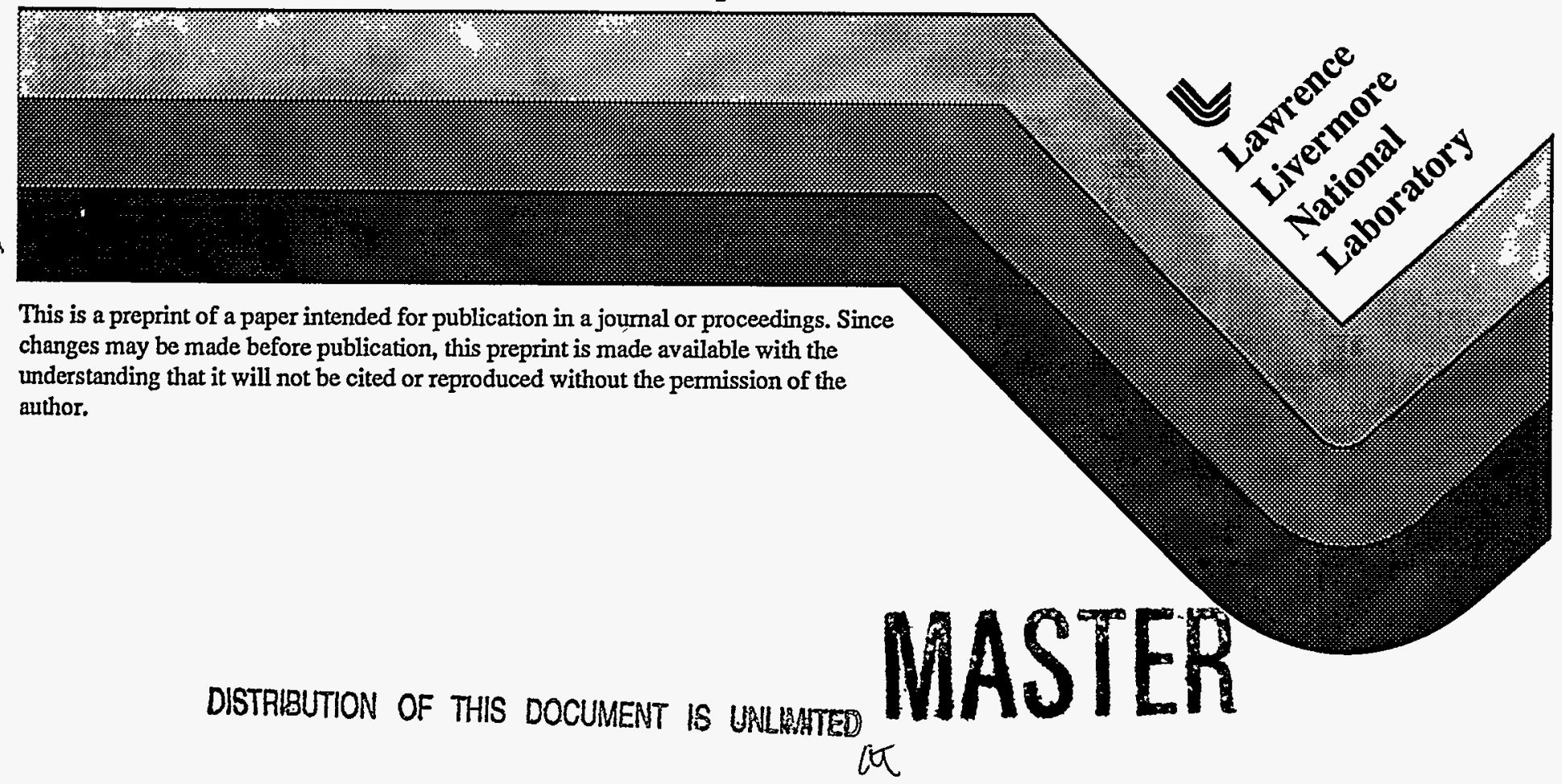




\section{DISCLAIMER}

This document was prepared as an account of work sponsored by an agency of the United States Government. Neither the United States Government nor the University of California nor any of their employees, makes any warranty, express or implied, or assumes any legal liability or responsibility for the accuracy, completeness, or usefulness of any information, apparatus, product, or process disclosed, or represents that its use would not infringe privately owned rights. Reference herein to any specific commercial product, process, or service by trade name, trademark, manufacturer, or otherwise, does not necessarily constitute or imply its endorsement, recommendation, or favoring by the United States Government or the University of California. The views and opinions of authors expressed herein do not necessarily state or reflect those of the United States Government or the University of California, and shall not be used for advertising or product endorsement purposes.

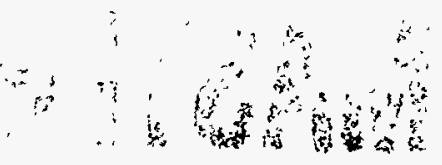




\title{
MULTIPLE MECHANISMS IN THE THERMALLY ACTIVATED PLASTIC FLOW OF TANTALUM
}

\author{
William H. Gourdin and David H. Lassila \\ Chemistry \& Materials Science Department, University of California, \\ Lawrence Livermore Nationai Laboratory, Livermore, California 94551
}

We argue that many of the features of the plastic flow behavior of tantalum can be described by a model that incorporates a two-component Peierls-type mechanism and an fcc-like obstacle mechanism in series. We compare the results of calculations based on such a model with flow data for unalloyed tantalum over a wide range of strain rates and a modest range of temperatures.

\section{INTRODUCTION}

As in other body-centered-cubic (bcc) metals, the mechanical properties of tantalum display marked temperature and strain-rate dependences (1-3). Based on observations of tungsten alloys, we recently suggested (4) that the presence of tungsten somehow suppresses the "Peierls" mechanism that dominates the initial flow stress, leaving only an "obstacle" mechanism similar to that found in facecentered-cubic (fcc) metals (5-7). From this, we infer that unalloyed tantalum plastic flow occurs via a series combination of thermally activated "Peierls" and "obstacle" barriers that are comparable in magnitude and hence dominate the flow in different regimes of deformation, strain rate, and temperature. Because the mechanical threshold associated with the obstacle mechanism increases with deformation, work hardening appears in a natural way. In this paper, we explore the viability of such a model by comparing calculated results to flow curves for unalloyed tantalum over a wide strain-rate range and a modest temperature range.

\section{MODEL DESCRIPTION}

To propagate plastic flow, a dislocation must overcome both obstacles and Peierls barriers, as illustrated in Fig. 1. The total transit time between two obstacles is the sum of the time needed to overcome the first obstacle and all the Peieris barriers in between. Assuming Boltzmann probabilities for overcoming the energy barriers. the transit time is

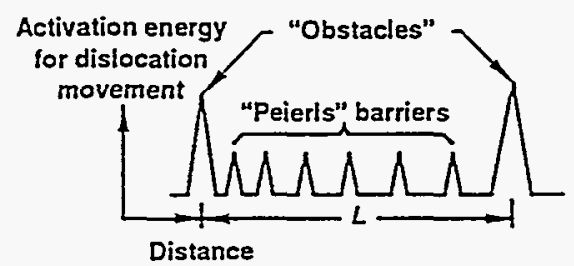

FIGURE 1. Schematic of two barriers to dislocation motion in series.

$$
\iota_{\mathrm{T}}=\left(\frac{1}{v_{0}}\right) \exp \left(\frac{G_{\mathrm{o}}}{k T}\right) \div\left(\frac{1}{v_{\mathrm{p}}}\right) n_{\mathrm{p}} \exp \left(\frac{G_{\mathrm{p}}}{k T}\right),
$$

where $v_{0}$ and $v_{\mathrm{p}}$ are the attempt frequencies and $n_{\mathrm{p}}$ is the number of Peieris barriers. The strain rate is proportional to the average dislocation speed $L / t \mathrm{~T}$ :

$$
\dot{\varepsilon}=\frac{\dot{\varepsilon}_{0}}{\exp \left(\frac{G_{0}}{k T}\right)+P \exp \left(\frac{G_{\mathrm{p}}}{k T}\right)}
$$

Equation (2) is the fundamental expression of the model that we propose for unalloyed tantalum.*

The activation free energy of the initial flow stress of tantalum as a function of the thermal stress $\sigma_{1}=\sigma-\sigma_{3}\left(\sigma_{2}\right.$ is the athermal stress) is shown in Fig. 2 (1). To reproduce the apparent rapid increase in $G_{\mathrm{p}}$ for very small $\sigma_{\mathrm{t}}$, we used the expression

\footnotetext{
* Dislocalion drag could easily be included in this expression. but it has litue iniluence under the conditions of our experiments.
} 


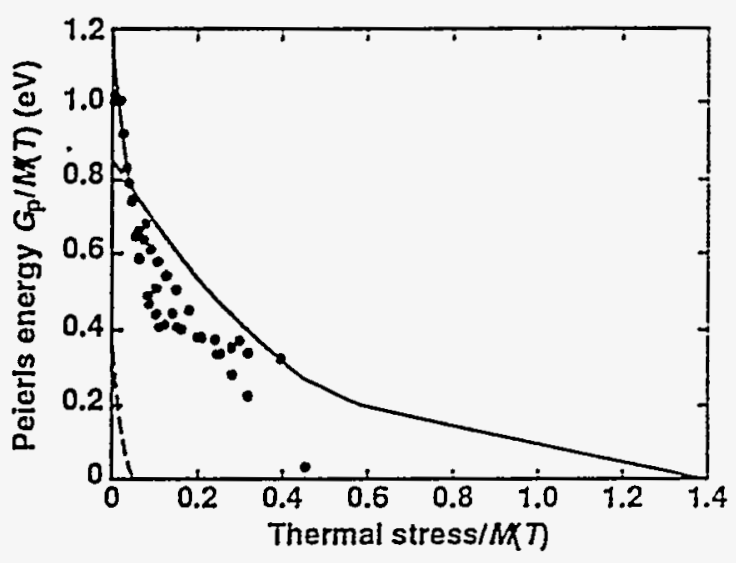

FIGURE 2. Activation energy at yield for unalloyed tantalum as a function of the themal portion of the applied stress.

$$
\begin{aligned}
G_{\mathrm{p}}= & G_{\mathrm{p} 1} f\left(\frac{\sigma_{\mathrm{t}}}{M(T) \hat{\sigma}_{\mathrm{p} 1}}\right) \\
& +G_{\mathrm{p} 2}\left[1-\left(\frac{\sigma_{\mathrm{t}}}{M(T) \hat{\sigma}_{\mathrm{p} 2}}\right)\right]^{2},
\end{aligned}
$$

where the secondary energy $G_{\mathrm{p} 2}$ and suress $\hat{\sigma}_{\mathrm{p} 2}$ are selected to agree with the data in Fig. 2.* We associate the first term with the Peierls energy reported in previous work, and the threshold stress associated with it, $\hat{\sigma}_{\mathrm{pl}}$, does not change with deformation. The function $f$ in this first term is close to the parabolic forms used elsewhere (2), but it deviates

\footnotetext{
* In this expression, the factor $M(T)=\mu(t) / \mu\left(T_{295}\right)$ normalizes the stresses to the temperature-dependent shear mociulus.
}

from this at large stresses to accommodate observed behavior at low temperatures and high strain rates.

The "obstacle" term in Eq. (2) is treated in a manner identical with that for copper $(6,7)$. The energy of activation over the barrier is given by

$$
G_{0}=G_{00}\left[1-\left(\frac{\sigma_{l}}{M(T) \hat{\sigma}_{0}}\right)^{p}\right]^{q} .
$$

The mechanical threshold $\sigma_{0}$ increases with deformation as prescribed by the empirical expression $(6,7)$

$$
\frac{d \hat{\sigma}_{\mathrm{o}}}{d \varepsilon}=\theta_{\mathrm{o}}\left[1-\frac{\tanh \left(\frac{2 \hat{\sigma}_{\mathrm{o}}}{\hat{\sigma}_{\mathrm{os}}}\right)}{\tanh (2)}\right] \text {, }
$$

and $\hat{\sigma}_{\text {os }}$ is given by

$$
\hat{\sigma}_{o s}=\hat{\sigma}_{o s 0}\left(\frac{\dot{\varepsilon}}{\dot{\varepsilon}_{s 0}}\right)^{1 / r},
$$

where $n=\mu(T) b^{3} \mathrm{~A} / k T$.

Equations (2) and (4)-(6) as well as a specified form for the function $f$ in Eq. (3) constitute the mathematical realization of the simple concept of

\begin{tabular}{|c|c|c|}
\hline Quantity & Description & Value/units \\
\hline$\mu$ & Temperature-degendent shear modulus: $\mu=\mu_{0}\left[1 \div W_{\mu}(T-300)\right]$ & $\overline{\mathrm{GPa}}$ \\
\hline$\mu_{0}$ & Shear modulus at $300 \mathrm{~K}$ & 69 \\
\hline$W_{\mu}$ & $d u / a T$ at $300 \mathrm{~K}$ & $-2.94 \times 10^{-}-\mathrm{x}^{-}:$ \\
\hline$c_{\mathrm{p}}$ & Temperanure-dependent specific heat: $c_{\mathrm{p}}=\left(4.1868 / \mathrm{M} \times \mathrm{B} \div 10^{-3} \mathrm{Cn}\right)$ & $\mathrm{J} / \mathrm{kg} / \mathrm{K}$ \\
\hline$M$ & Molecular weight & $180.948 \times 10^{-j} \mathrm{~kg} / \mathrm{mac}$ \\
\hline B & $c_{p}$ coefficient & $5.82 \mathrm{cal} / \mathrm{mol}$ \\
\hline C & $c_{2}$ coefficient & $0.78 \mathrm{cal} / \mathrm{mol}$ \\
\hline$\dot{b}$ & Burgers vector & $2.86 \times 10^{-i 0} \mathrm{~m}$ \\
\hline$k / b^{3}$ & Boizzmann's constant divided by $\dot{\sigma}^{3}$ & $5.9 \times 10^{-} \mathrm{GPaK}$ \\
\hline$p$ & Oostacie activation encrgy exponent & 23 \\
\hline$q$ & Obstacle activation energy exponent & : \\
\hline$\dot{\varepsilon}_{0}$ & Surain-rate pre-exponential & $10^{i} s^{-:}$ \\
\hline$g_{00}$ & Dimensioniess obstacle acsivation: $g_{\infty 0}=G_{\infty 0} / \mu(295 \mathrm{~K}) b^{3}$ & 0.694 \\
\hline
\end{tabular}
Fig. 1. Parameter values are collected in Tables I and 2 , and the curve for the function $f$ in Eq. (3) is shown in Fig. 2. We take $P=1$ in Eq. (2).

TABLE 1. Phvsical Constants and Non-adiustable Model Parameters 
TABLE 2. Adiustable Model Parameters

\begin{tabular}{cccl}
\hline Parameter & Units & Equation/Definition & Value \\
\hline$\sigma_{2}$ & $\mathrm{GPa}$ & $\mathrm{q}=\sigma-\sigma_{2}$ & 0.055 \\
$g_{\mathrm{p} 1}$ & - & $g_{\mathrm{pl}}=G_{\mathrm{p} 1} / \mu(T) b^{3}$ & 0.0817 \\
$\hat{\sigma}_{\mathrm{p} 1}$ & $\mathrm{GPa}$ & 3 & 1.4 \\
$g_{\mathrm{p} 2}$ & - & $g_{\mathrm{p} 2}=G_{\mathrm{p} 2} / \mu(T) b^{3}$ & 0.0341 \\
$\hat{\sigma}_{\mathrm{p} 2}$ & $\mathrm{GPa}$ & 3 & 0.056 \\
$\hat{\theta}_{\mathrm{p} 2}$ & $\mathrm{GPa}$ & 7 & 6.2 \\
$\hat{\sigma}_{\mathrm{p} 10}$ & $\mathrm{GPa}$ & 7 & 1.3 \\
$\hat{\theta}_{0}$ & $\mathrm{GPa}$ & 5 & 6.8 \\
$\hat{\sigma}_{\mathrm{os} 0}$ & $\mathrm{GPa}$ & 6 & 0.605 \\
$\mathrm{~A}$ & - & - & 0.118 \\
\hline
\end{tabular}

\section{RESULTS AND COMPARISON TO EXPERIMENTAL DATA}

Ingots of unalloyed tantalum* were forged, rolled, and annealed to yield material with a uniform grain size of 35 to $38 \mu \mathrm{m}$. Cylindrical specimens $0.5 \mathrm{~cm}$ in dia. by $0.5 \mathrm{~cm}$ high were prepared and tested on a conventional hydraulic test machine and a compressive split Hopkinson pressure bar (SHPB).

Calculations at $298 \mathrm{~K}$ with constant $\hat{\sigma}_{\mathrm{pl}}$ and $\hat{\sigma}_{\mathrm{p} 2}$ are compared with our data in Fig. 3 . The model reproduces the initial yield stresses very well, and at large strains, the agreement remains reasonably good because obstacle hardening eventually becomes the dominant mechanism. At smaller strains where the Peierls mechanism dominates, however, plateaus of constant flow stress much wider that those observed dominate the calculated flow curves. To remedy this, we allowed the threshold stress $\hat{\sigma}_{\mathrm{p} 2}$ in Eq. (3) to increase with deformation according to

$$
\frac{d \hat{\sigma}_{\mathrm{p} 2}}{d \varepsilon}=\theta_{\mathrm{p} 2}\left(1-\frac{\hat{\sigma}_{\mathrm{p} 2}}{\hat{\sigma}_{\mathrm{p} 20}}\right)^{0.70} .
$$

This expression has no physical meaning of which we are aware, and we have selected it because it has a form consistent with data at $77 \mathrm{~K}$ (Fig. 4).

Flow curves recalculated with this modification are compared with the experimental data in Figs. 4 and 5. At room temperature (Fig. 5), the improvement in the agreement at intermediate strains is striking. Similarly, the description of the SHPB results (Fig. 4) is much improved, with modest hardening controlled by Eq. (7) a prominent feature.

\footnotetext{
* Cabol Corporacion, Boyerstown, Pennsylvaniz, LSA.
}

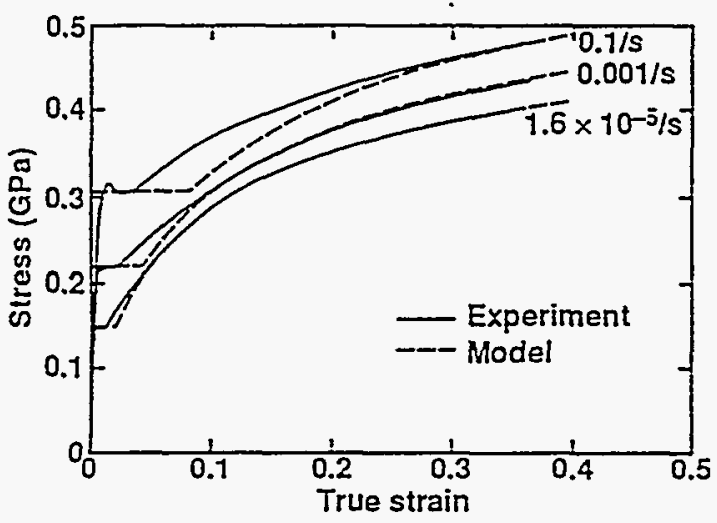

FIGURE 3. Comparison of model calculations for constant $\hat{\sigma}_{\text {l }}$ and $\hat{\sigma}_{p 2}$ with experimental observations for various strain rates at $298 \mathrm{~K}^{\mathrm{P}}$ Calculations assume deformation take place isothermally.

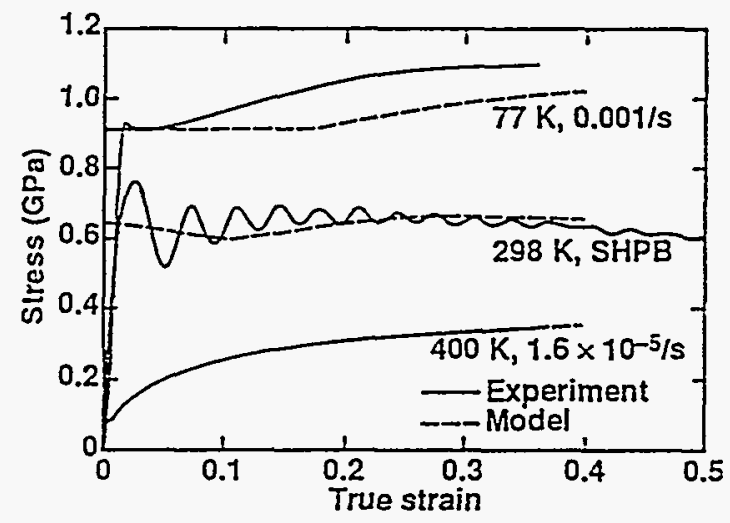

FIGURE 4. Comparison of model calculations for constant $\hat{\sigma}_{\text {t }}$ and variable $\hat{\sigma}_{2}$ [Eq. (7)] with experimental observations for ${ }^{\text {? }}$ high and low strain rates at various temperatures. Deformations at 400 and $77 \mathrm{~K}$ are assumed to take place isothermally, but the SHPB experiment is assumed to be adiabatic.

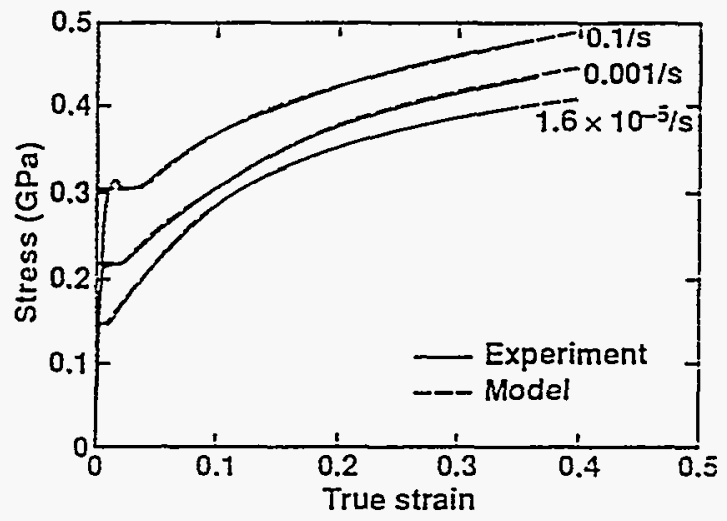

FIGLRE 5. Comparison of model caiculations for constant $\hat{\sigma}_{\text {. }}$ and variable $\hat{\sigma}_{\mathrm{p} 2}\left\{\right.$ [Eq. (7)] with experimental observations for ${ }^{2}$ various strain rảtes at various temperatures. Calculations assume deformation takes place isothermally. 
Some hardening of the flow stress at $77 \mathrm{~K}$ is also apparent, but here the agreement is not completely satisfactory. As expected, the introduction of Eq. (7) has no effect on the flow curve at $400 \mathrm{~K}$ (Fig. 4 ) because the obstacle term dominates all but a very limited initial flow regime.

\section{DISCUSSION}

Our model describes the initial flow stress of tantalum well over a wide range of strain rate and a modest range of temperature. Although the curve for $G_{\mathrm{p}}$ given in Fig. 2 falls slightly above the data of Conrad (1), the agreement is acceptable, in view of the sensitivity of the flow stress of tantalum to solutes and interstitials. Certainly the value of $G_{p 1}$ that we find (Table 2) is within the range of values reported in the literature $(2,8-10)$.

Screw dislocations are a characteristic of the microstructure of deformed bcc metals and are known to carry much of the plastic deformation, particularly at low temperatures $(10,11)$. While this provides a structural rationalization for the dominance of the Peierls mechanism in determining the initial flow stress in tantalum, the secondary term proposed in Eq. (3) has no such obvious analog. One plausible suggestion is the noncoplanar dissociation of the dislocation core $(2,8)$, but the magnitude of the activation energy associated with such a mechanism has not been estimated. Furthermore, it is not clear why $\sigma_{\mathrm{p} 2}$ should increase with increasing deformation. Nevertheless, calculations clearly show that our model can describe at least semi-quantitatively the crossing of the hardening curves for unalloyed tantalum noted in (4). It thus may provide a natural explanation for this otherwise puzzling behavior of the hardening as a function of strain rate.

At low strain rates or elevated temperatures, obstacles appear to dominate the flow curves after initial yield. The shape of such flow curves, determined by Eq. (5), applies equally well to both bcc and fcc metals. This suggests that the mechanism of plastic flow, broadly speaking, is the same for both materials under these deformation conditions.

\section{CONCLUSIONS}

Our model provides a plausible framework for describing the well-known yield behavior of bce metals and their hardening in an integrated and physically motivated manner. From this work, we conclude the following:
- Deformation of unalloyed tantalum is controlled by a series combination of (1) a "Peieris" mechanism with a small activation energy $(0.5-1.0 \mathrm{eV})$ and a large threshold stress ( $-1.0 \mathrm{GPa})$ and (2) an "obstacle" mechanism with a large activation energy $(-10 \mathrm{eV})$ and a small threshold stress that increases with deformation.

- The Peieris term consists of a larger and dominant component $(0.85 \mathrm{eV})$ associated with a constant threshold stress $(1.4 \mathrm{GPa})$ and a smaller component $(0.35 \mathrm{eV})$ associated with an initially small threshold stress.

- To reproduce the flow behavior of unalloyed tantalum at intermediate strains, this secondary threshold stress must increase with deformation.

- At very low strain rates or elevated temperatures, hardening of unalloyed tantalum can be described by the same relationships as obstacle hardening in fcc metals.

\section{ACKNOWLEDGMENTS}

We thank M. LeBlanc and D. Shieldis for performing the experiments for this siudy. Work was performed under the auspices of the U.S. Department of Energy by the Lawrence Livermore National Laboratory under Contract No. W-7405-Eng-48.

\section{REFERENCES}

1. Conrad, H., "The cryogenic properies of metals," in High Strength Materials, V. F. Zacksy, ed. New Yori, Wiley, 1965), Ch 11, pp. 436-509.

2. Hoge, K. G., and Mukherjes, A. K., J. Mater. Sci. 12 , 1666-1672 (1977).

3. Christian, J. W., Metall. Trans. A 14A 1237-1256 (1983).

4. Gourdin, W. H., Lassila, D. H., LeBlanc, M. .H., and Shicids, A. L., J. Phys. (Poris) $N$ CS, 207-212 (1994).

5. Chen, S. R., and Gray, G. T., III, "Consututive behavior of tungsten and tantzlum, experiments and modeling," Los Alamos National Laboratory, Los Alamos, NM, LA-LR94-3405, presented at 1994 Intemational Conference on Tungsten and Refractory Metals, McLean VA. October 1:19. 1994.

6. Follansbee, P. S., and Kocks, L. F., Acta Metall. 36, S1-03 (1988).

7. Gourdin, W. H., and Lassila, D. H., Acta Wetoll. et Moter. 39, 2337-2348 (1991).

3. Christian, J. W., and .lasters, B. C. Proc. Roy. Soc. A 281. 240-257 (1964).

9. Wemer, M., Phys. Stat. Sol. 104, 63-7S (1987).

10. Mizubayashi, H., Egashira, H., and Okuda, S., Acta Metcii. et Mater. 13 (1) 269-276 (1994).

:1. Johnson, P. E., "The Structural Depencence of Work Hardening in Low Carion Steels," Lawrence Berixeley Laboratory, Berkeley, CA. LBL-31670 (199!:. 


\title{
AN IN SITU HIGH VOLTAGE ELECTRON MICROSCOPY TECHNIQUE FOR THE STUDY OF DEFORMATION AND FRACTURE: IN MULTILAYERED MATERIALS
}

\author{
M.A.. WALL, T.W. BARBEE, Jr. and T.P. WEIHS \\ Chemistry and Materials Science Department, L-350, Lawrence Livermore National Laboratory \\ Livermore, CA. 94550.
}

\begin{abstract}
A novel, in situ, high voltage electron microcopy technique for the direct observation of the micromechanisms of tensile deformation and fracture in nanostructured materials is detailed. This technique is particularly well suited for the dynamic observations of deformation and fracture in multilayered materials. The success of this type of in situ technique is highly dependent upon unique specimen preparation procedures and sample design, the importance thereof will be discussed. The initial observations discussed here are expected to aid in our understanding of the mechanical behavior of this new class of atomically engineered materials.
\end{abstract}

\section{INTRODUCTION}

The success of Transmission Electron Microscopy (TEM) as a characterization tool in providing the link between a materials microstructure and physical properties is due to its unparalleled spatial resolution. However, one limitation of.conventional TEM is that most observations are only static or "postmortem", allowing only indirect conclusion about the mechanisms of microstructural evolution. In situ High Voltage Electron Microscopy (HVEM) techniques allow for the possibility of overcoming this limitation through direct observation of -materials under dynamic conditions [1]. The development and success of in situ experiments hinge upon the proper use and design of instrumentation, and the iterative development of specimen preparation and sample design procedures.

Nanostructured, multilayered materials, often exhibit novel and improved mechanical properties [2]. Multilayered materials are dramatically stronger and harder then conventionally processed materials of similar composition. The high strength of these new materials is attributed to their layered, nanoscale structure and a variety of related strengthening mechanisms. Their layered variations in composition, stiffness, residual elastic strain, crystal structure and interfacial defects are expected to impede dislocation glide between layers, while inner layer grain boundaries and their nanoscale layer thickness restricts dislocation motion within layers. Mechanical test data suggest that some of these strengthening mechanisms are active in multilayered materials [3]. However, none of the mechanisms have been confirmed directly in these materials. A number of in situ HVEM deformation and fracture studies have been performed on conventionally processed "bulk" structures [4]. To date there has been no reported work successfully applying in situ TEM tensile deformation techniques to nanostructured multilayered materials, most probably because of the limitations of specimen preparation and sample design considerations.

\section{MATERIALS AND METHODS}

The sample from which our cross-sectional tensile specimens are made is a copper $(\mathrm{Cu})$ $(80.0 \mathrm{~nm}) /$ zirconium $(\mathrm{Zr})(8.7 \mathrm{~nm})$ multilayer foil containing 1250 periods for a total thickness of $\approx 120$ microns. The $\mathrm{Cu} / \mathrm{Zr}$ multilayer was synthesized by planar magnetron sputtering onto a glass substrate. The in situ deformation experiments were performed using a standard tensile deformation stage in the Kratos 1.5 MeV HVEM located at the National Center for Electron Microscopy, Lawrence Berkeley Laboratory, CA. 


\section{EXPËRIMENTAL}

\section{A: Sample Design}

In designing a multilayer sample for in situ HVEM tensile deformation studies, several parameters were considered: layering materials, repeat period and total thickness. The selection of $80 \mathrm{~nm}$ of $\mathrm{Cu}$, a ductile metal layer, and $9 \mathrm{~nm}$ of $\mathrm{Zr}$, a much harder metal layer, was chosen to produce a layered microstructure. Because the mechanical properties of these materials are dramatically different, it is anticipated that the deformation and failure mechanisms of these materials will be different. The period of the sample was held below $100 \mathrm{~nm}$ so that the microstructure is in the class of nanostructured materials, but the layers are large enough to facilitate imaging in the HVEM under conventional conditions and moderate magnifications. The total thickness of the multilayer foil was increased significantly over typically synthesized multilayer films to facilitate handling during the specimen preparation procedure. General characterization of the as-deposited microstructure has been reported by [5].

\section{B: Specimen Preparation}

To prepare a multilayer sample in cross section for in situ straining, a modified version of a technique described by Wall [6] was employed. The basic steps for preparation include: electroplating, slicing, lapping, dimpling, low angle ion milling and focused ion beam milling. The steps will be discussed in sequence.

First, the multilayer sample is released from its substrate by scratching the surface of the film near the edge of the substrate and pulling away. A rectangular strip measuring $4 \mathrm{~mm}$ by $10 \mathrm{~mm}$ is cut from the free standing sample. This strip is then electroplated with $\mathrm{Cu}[6]$ to the minimum dimensions $4 \mathrm{~mm}$ by $10 \mathrm{~mm}$ by $10 \mathrm{~mm}$, Fig. 1 . A rectangular shaped block measuring $4 \mathrm{~mm}$ wide, -by $10 \mathrm{~mm}$ long, by $10 \mathrm{~mm}$ high, is machined from the rough deposit, Fig.2. Using a low speed diamond saw, $.25 \mathrm{~mm}$ thick slices are cut perpendicular to the multilayer sample embedded in the electroplated $\mathrm{Cu}$ deposit. The slices are then lapped equally from both sides. with a succession of finer lapping paper $\left(\mathrm{Al}_{2} \mathrm{O}_{3}, 30,12\right.$ and $\left.3 \mu \mathrm{m}\right)$ to a final thickness of $150 \mu \mathrm{m}$. The samples are then dimpled directly on top of the mulitlayer using 600 grit $\mathrm{SiC}$ followed by $4 \mu \mathrm{m}$ cubic boron nitride to a remaining thickness of $20 \mu \mathrm{m}$, Fig. 3. Final thinning to electron transparency is performed in two steps. First, low angle ion milling ( $6^{\circ}$ angle of incidence) in combination with sector speed control is performed until a perforation exists at one of the multilayer-Cu plating interface. Low angle ion milling is performed on a Dual Ion Mill*. This is possible by making modifications to the specimen support platens. The bottom platen hole is enlarge to a $6 \mathrm{~mm}$ diameter and the top clamping plate is not utilized. Duco cement is used to hold the specimen in place. These two modifications are necessary so the specimen platens does not cast an ion beam shadow over the cross-sectional specimen at low ion milling angles. The last step is the use of focused ion beam milling (FIBM) using a PIMS*. The FIBM is used to "notch" a micro gauge section in the thin region of the multilayer. The parameters for FIBM are: $10 \mathrm{KeV}, 2 \mu \mathrm{m}$ diameter spot size and $>45$ degrees angle of incidence. The notch dimensions used to date measure approximately $7 \mu \mathrm{ms}$ wide by one half to two thirds the multilayer width. Figure 3 is a low magnification SEM image of a notched specimen. Figure 4, point $\mathrm{P}$ is the electron transparent micro gauge section and the location at which deformation and failure is anticipated to be observed.

\section{In situ tensile procedure}

The tensile specimens are mounted on the platens of the straining stage with 5 minute epoxy. The straining stage is then inserted into the HVEM and tilted so that the layers are viewed on edge. Since the $\mathrm{Cu}$ and $\mathrm{Zr}$ grains have a [111] and [0002] growth texture, the average imaging conditions of most grains are near $\mathrm{BF}$ diffraction conditions. The specimens are elongated at a rate 
of approximately .1 to $.2 \mu \mathrm{m} / \mathrm{second}$. Straining is stopped intermittently to observe the deformation events and for recording on film the microstructural changes. The dynamic events are recorded on video format using a high resolution video camera and recorder attached to the HVEM.

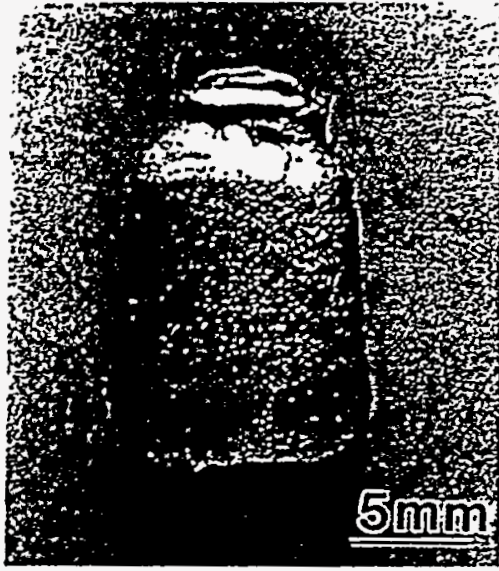

Fig. 1, Copper electroplated multilayer foil sample.

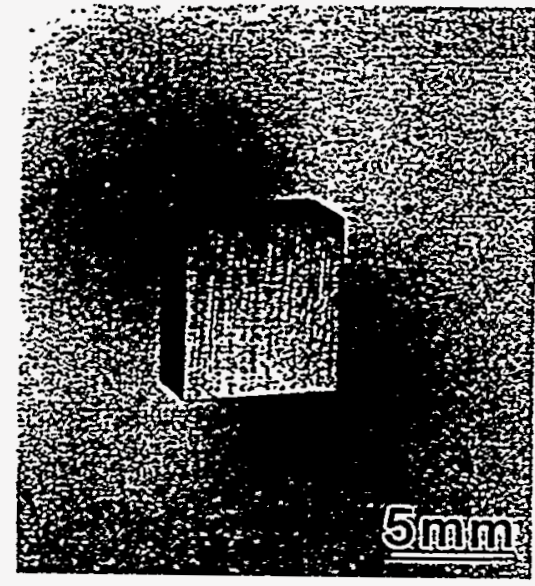

Fig. $2,4 \mathrm{~mm} \times 10 \mathrm{~mm} \times 10 \mathrm{~mm}$ block cut from $\mathrm{Cu}$ plating. containing the multilayer foil.

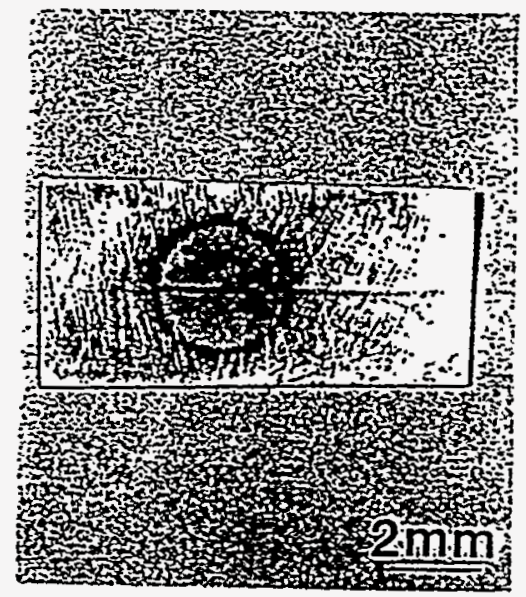

Fig. 3, Sliced, lapped and dimpled specimen ready for ion milling.

\section{OBSERVATIONS}

Figure 5 shows a completed cross-section specimen ready for in situ HVEM tensile deformation studies. The micro gauge section can be seen in this low magnification TEM micrograph. The electron transparent region to be viewed during tensile testing is located at the bottom of the notch, see point $P$ in Fig. 4.

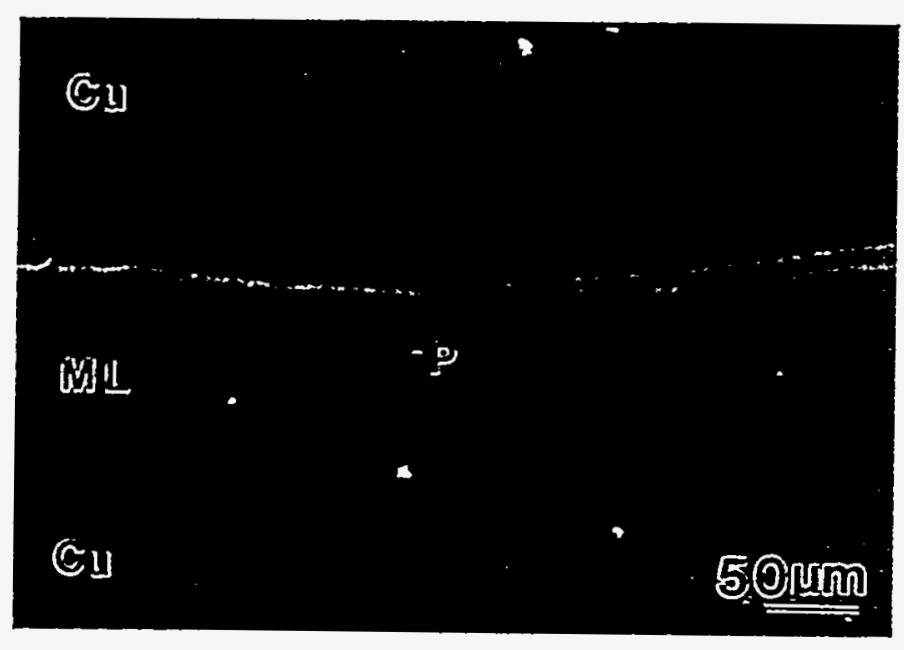

Fig. 4, Scanning electron micrograph of the multilayer viewed in cross-section showing the micro gauge section. Point $P$ is the TEM viewing region.

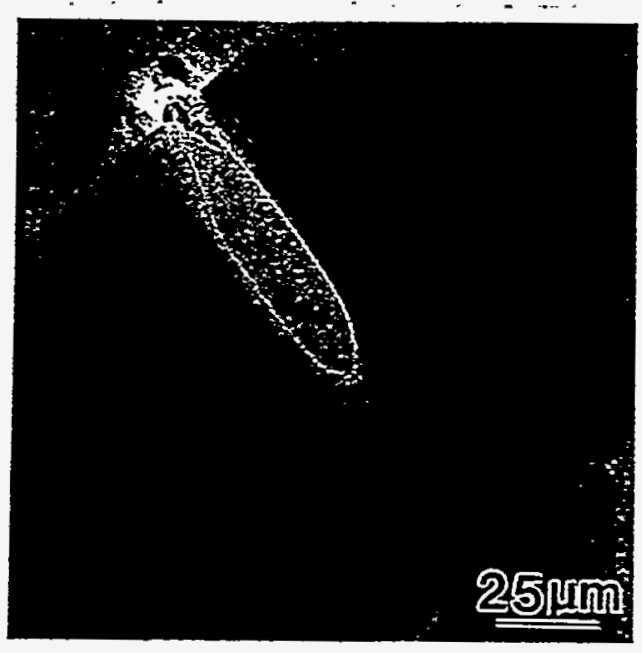

Fig. 5, Low magnification TEM image of the micro-gauge section.

The results of a successful in situ straining test are seen in figure 6 The as-deposited structure viewed in cross-section is shown in figure 6a. The structure is well layered. The $\mathrm{Cu}$ and 
$\mathrm{Zr}$ grain sizes are within a factor of 2 of the $80 \mathrm{~nm}$ and $8.7 \mathrm{~nm}$ layer thicknesses respectively. During initial straining, dislocation motion was observed throughout the electron transparent region within the $\mathrm{Cu}$ layers. Dislocations were observed to initiated within $\mathrm{Cu}$ grains and quickly disappear, going out of contrast at $\mathrm{Cu}-\mathrm{Cu}$ or $\mathrm{Cu}-\mathrm{Zr}$ grain boundaries. Continued straining resulted in the failure of several $\mathrm{Zr}$ layers forming a row of voids, Fig. $6 \mathrm{~b}$. These voids are fairly uniform in size $(8.7 \mathrm{~nm})$ but get smaller towards the crack tip. At this point it appears that the $\mathrm{Zr}$ layers failed with little or no deformation. The $\mathrm{Cu}$ layers in between the voids have deformed locally to form a row of ligaments. This combination of ligaments and voids resulted in the formation of a crack. The crack nucleated at the edge of the specimen at the bottom of the notch. The crack propagated in a direction perpendicular to the layering and loading direction into the thicker region of the specimen. Further tensile loading results in the growth of the voids as the Cu ligaments elongated and necked down. The crack continues to propagate into the specimen by the nucleation and growth of more voids in front of the crack, Fig. 6c. With the nucleation and growth of the crack, deformation has become highly localized; primarily in the region in front of and around the crack tip. With continued tensile loading the $\mathrm{Cu}$ ligaments fail and the crack continues to propagate leading to the eventual failure of the multilayer across the micro gauge section.

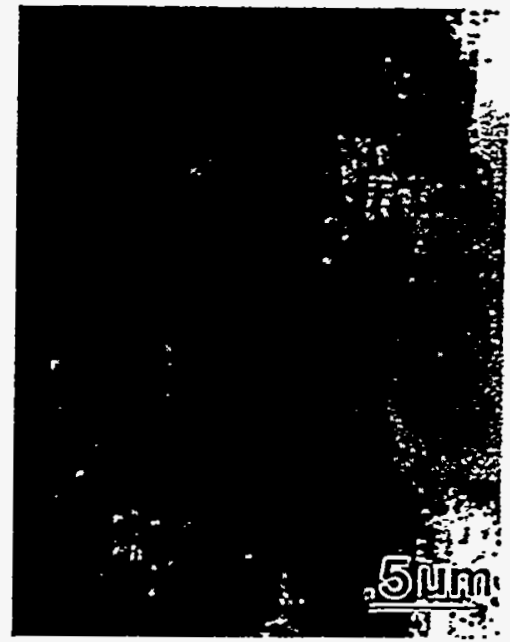

Fig. 6, A) BF TEM micrograph of the as-deposited $\mathrm{Cu} / \mathrm{Zr}$ multilayer structure viewed in cross-section.

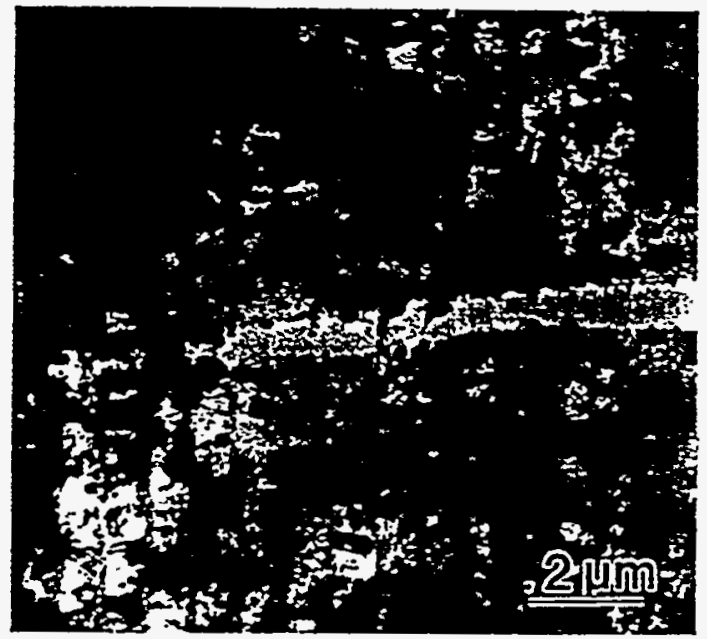

Fig. 6, B) BF TEM micrograph of the initial crack formation. A row of voids in $\mathrm{Zr}$ layers and a bridge of $\mathrm{Cu}$ ligaments have formed.

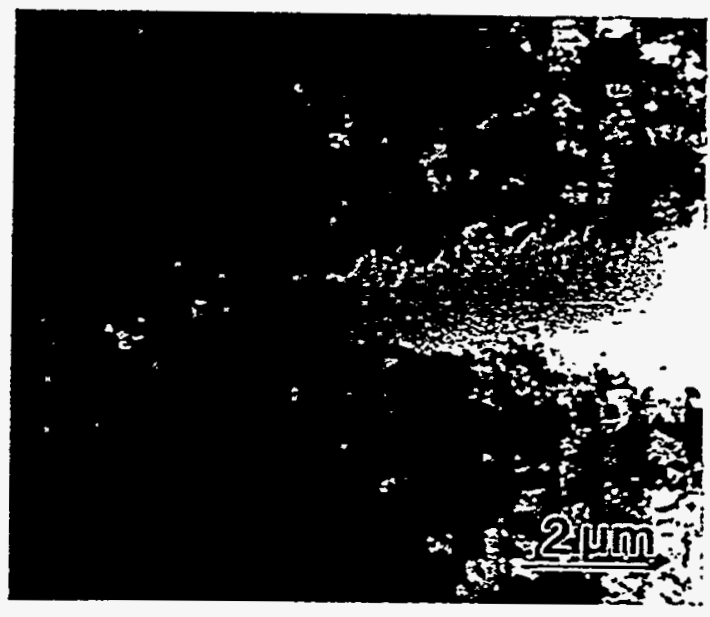

Fig. $6 \mathrm{C}$ ) Crack propogation into the thicker region of the sample with continued straining. The $\mathrm{Cu}$ layers have failed and voids continue to form in the $\mathrm{Zr}$ layers in front of the crack tip. 


\section{DISCUSSION}

The potential of in situ HVEM experimentation has long been recognized, but these experiments required rigorous methodology [7]. The success of our in situ procedure is dependent upon the synergistic combination of specimen preparation, sample design and the use of specialized in situ TEM instrumentation.

The development of a unique specimen preparation solution was the single most important step. The modified application of a procedure described earlier by Wall [6], resulted in the ability to prepare the multilayers in cross section for tensile loading in the HVEM. Focused ion beam milling was used to create a micro gauge section. This resulted in the ability to predetermine the location at which deformation, crack nucleation, growth and failure would be observed and recorded at high magnifications in the HVEM. Prior to the FIMB step we were not able to successfully determine and view the location at which initial deformation and failure occured.

The design parameters of the $\mathrm{Cu} / \mathrm{Zr}$ multilayer sample proved to be beneficial as expected. The large total thickness of the film allowed for the handling of the multilayer foil sample throughout the specimen preparation procedure without damage. This particular combination of materials resulted in the observation of scientifically interesting deformation and failure mechanisms, ie. the nucleation and growth of a crack across a nanostructured, layered material.

Although not detailed in great length in this report, the benefits of utilizing proper instrumentation can never be overlooked. The use of an HVEM operating at 1.5Mev allows for imaging through regions of the specimens which are three to five times thicker than the microstructural periodicity. This in turn, facilitates the comparison of these observed behaviors to those in bulk materials. The tensile stage used here allowed for the fixturing of a relatively large specimen. The stage also has a high loading capacity and actuates smoothly during operation. The use of a video system allowed for the recording of dynamic events that other wise could not be captured and displayed in micrograph form.

In a thin TEM specimen the stress state with the layering will not be identical to that of the bulk multilayer foil. However, when the TEM specimen thickness is several times larger that the multilayer period the stress state begins to resemble that of the bulk material and we believe that there are qualitative observations that can be made. Prior to crack nucleation the strain rate was $\sim 10^{-2} / \mathrm{sec}$. Dislocations were observed to move within the $\mathrm{Cu}$ layers through out the micro gauge section. The estimated plastic strain within the $\mathrm{Cu}$ layers is $\sim 1 \%$. The dislocations appeared to move a short distances $(100 \mathrm{~nm})$ before going out of contrast when slipping to another Cu grain with different imaging conditions or becomming pinned at $\mathrm{Cu}-\mathrm{Cu}$ or $\mathrm{Cu}-\mathrm{Zr}$ grain boundaries. The grains in the $\mathrm{Cu}$ layers are textured (111) plane growth, the three remaining $\{111\}$ planes all have Burgers vectors with favorable Schmidt factors for easy slip. No dislocations were observed to move within or across the $\mathrm{Zr}$ layers; rather, just confined to the $\mathrm{Cu}$ layers. With a grain size $<10 \mathrm{~nm}$ it appears that nucleation and motion of dislocations within the $\mathrm{Zr}$ layers is depressed. The Zr grains are textured (0001) plane growth; the Schmidt factors for basel plane slip are very low; therefore a secondary slip system would have to be activated for deformation to occur in the $\mathrm{Zr}$ layers. It is also possible that we could not image such dislocation in these small grains at the current working magnification for these experiments.

After initial plastic deformation, a crack has nucleated by the failure of a series of $\mathrm{Zr}$ layers. The $\mathrm{Zr}$ layers fail in what appears to be a brittle, transgranular mode. The $\mathrm{Zr}$ layer failure sites form a row of voids and leave a bridge network of $\mathrm{Cu}$ ligaments. The voids now become nucleation sites for ductile failure of the Cu layers. This combination of voids and ligaments form a mode 1 crack, perpendicular to the layering. Once this initial crack is nucleated the plastic deformation becomes more localized to the regions in front of and along the crack. The crack continues to grow perpendicular to the layering with continued applied straining. Crack growth is continued through void growth by necking of the $\mathrm{Cu}$ ligaments, and formation of additional voids in the $\mathrm{Zr}$ layers 2 to 3 periods in front of the crack tip. The remaining $\mathrm{Cu}$ ligaments continue to elongate and eventually fail after $\sim 200 \%$ plastic strain.

In the propagation of a ductile crack in bulk materials voids nucleate and grow ahead of the 
crack tip within distances of the order of the crack tip opening. In the observations reported here the periodic array of $8 \mathrm{~nm}$ thick low ductility $\mathrm{Zr}$ layers fail first thereby acting as sites for ductile void nucleation. The still continuous thicker $\mathrm{Cu}$ layers $(t=80 \mathrm{~nm})$ then deform leading to ductile void growth required for crack propagation. The magnitude of the ductile void growth required for crack propagation is clearly shown to be determined by the multilayer period in these observation. Thus deformation energy dissipated in the crack propagation is directly related to the scale of the imposed multilayer microstructure ie. the multilayer period. We believe it will therefore be possible to directly relate the microscopic behavior as observed in the in situ studies of crack propagation in multilayered materials to the results of fracture toughness studies of such multilayered materials in bulk form.

\section{CONCLUSION}

An experimental technique for in situ HVEM straining of multilayers in cross-section has been described. This technique is reproducible and applicable to other multilayer and thick film systems. The success of this technique is highly dependent upon sample design, the development of a unique specimen preparation procedure and the use of specially designed instrumentation. Fabrication of a micro gauge section to pre-locate the region in which deformation and fracture will occur was the single most important step. This step is adaptable to other in situ straining experiments when it is unknown where the dynamic deformation events will take place. The observations reported here are unique and will aid in the understanding of the micromechanisms of deformation and fracture of nanostructured materials.

\section{ACKNOWLEDGMENTS}

The authors wish to thank Richard Gross of Lawrence Livermore National Laboratory for his technical support and the National Center for Electron Microscopy for their technical support and facilities. This work was performed under the auspices of the US Department of Energy by the Lawrence Livermore National Laboratory under contract W-7405-Eng-48.

* Product of Gatan Inc., 6678 Owens Drive, Pleasanton, Ca., USA.

\section{REFERENCES}

1) Butler, E. P., in Proceedings of the 38th Electron Microscopv Society of America, (Claton Publishing Div., Baton Rouge, Louisiana, 1980), p. 12-15.

2) Suryananayana, C. and Froes, F.H., Metallurgical Transactions A, 23A:1071-1081, (1992).

3) Grilhe, J., in Mechanical properties and deformatiom behavior of materials having ultra-fine microstructures, (Kluwer Academic Publishers, Boston, Ma, 1993), p. 255-286.

4) Messerschmidt, U., (1989) Electron microscopy in plasticitv and fracture research of materials, (Akademie-Verlag Publishers, Berlin).

5) Weihs, T.P., Wall, M.A. and Barbee, Jr., T.W. in Proceedings of the Materials Research Society Symposium, (Mater. Res. Soc. Proc. 308, Vol. 308, 1994), p. 753-758.

6) Wall, M.A., Microscopy Research and Technique, 27:262-267, (1994).

7) Butler, E. P.,in Proceedings of the 47th annual meeting of the electron microscopv socierv for america, (San Francisco Press publishers, San Francisco Ca, 1989). p. 610-611. 

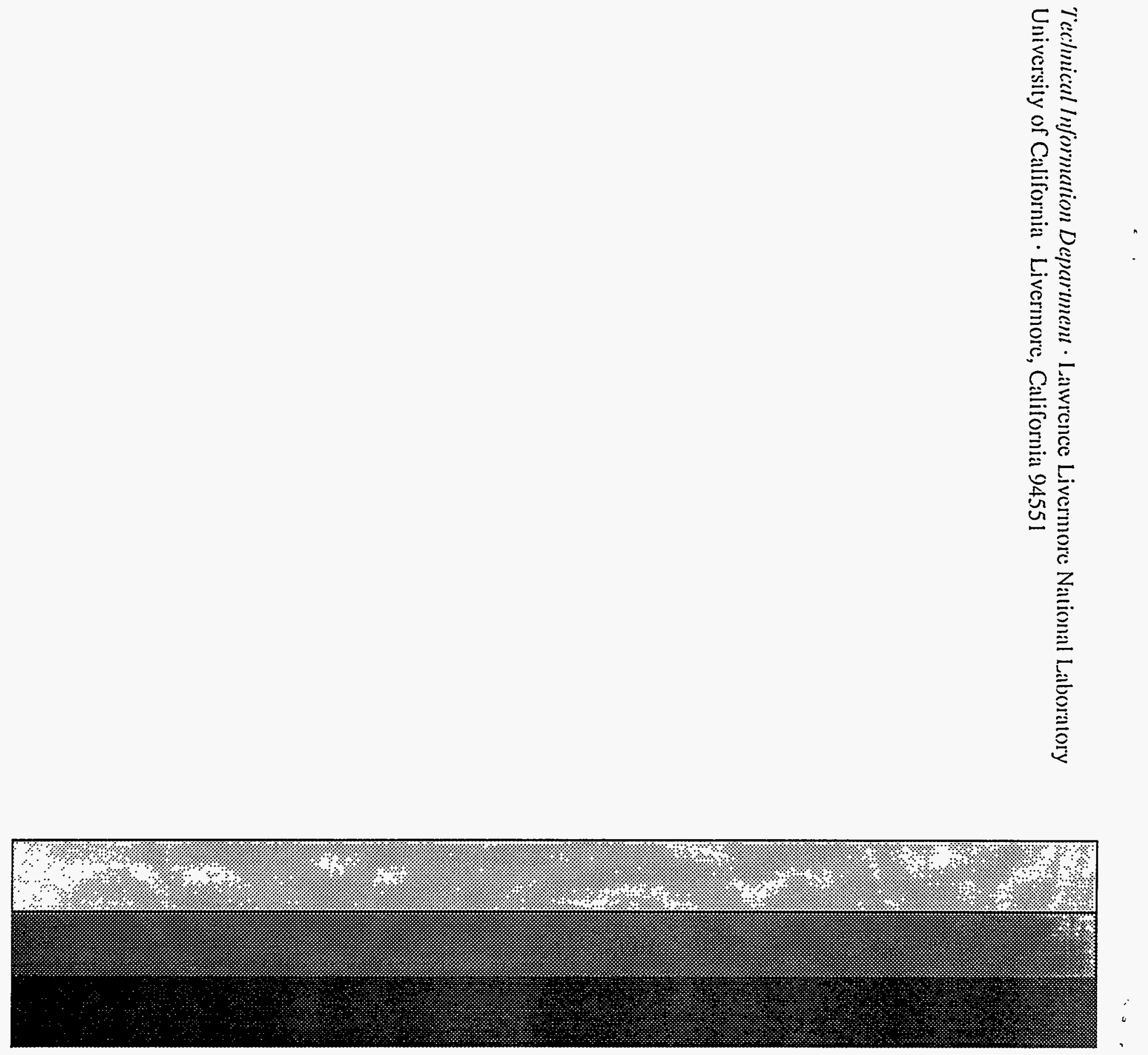